\title{
Estimation of the risk under the accident that hexamethylenetetramine flows out to the river due to a direct earthquake
}

\author{
S. HAMAMOTO $^{1 *}$, L. ITO $^{1}$, N. YONEYAMA ${ }^{2}$, A. TOKAI $^{1}$ \\ ${ }^{1}$ Osaka University, Division of Sustainable Energy and \\ Environmetal Engineering, Graduate school of \\ Engineering, 2-1 Yamadaoka, Suita, Osaka, Japan \\ ${ }^{2}$ Disaster Prevention Research Institute, Kyoto University, \\ Research Center for Fluvival and Coastal \\ Disaster, Gokasho, Uji, Kyoto, Japan \\ (*correspondence: hamamoto@em.see.eng.osaka-u.ac.jp)
}

Natech (Natural-hazard triggered technological accidents) events often happen in the world, but it has not been well prepared and evaluated. In 2012, untreated hexamethylentetramine $\left(\mathrm{C}_{6} \mathrm{H}_{12} \mathrm{~N}_{4}\right)$ was discharged into the Tone River, which distributes water in the metropolitan area in Japan, resulting in the detection of formaldehyde $\left(\mathrm{CH}_{2} \mathrm{O}\right)$ that exceeds the water quality standard due to a chemical reaction with chlorine in the water purification tank. When assessing the Natech accident, it is important to construct a scenario that takes such chemical reactions into consideration. However, the behavior of chemicals that have been released to the environment under unusual conditions and their impacts on water purification plant have not been clarified. Therefore, we assess the risk of chemical reaction in the water purification plant in case that $\mathrm{C}_{6} \mathrm{H}_{12} \mathrm{~N}_{4}$ flows out to the river from the industrial plant due to the earthquake in Osaka where the active faults are developed.

We selected the plants that handle those chemicals and calculated the outflow rate which will release into the Yodoriver, the largest water supply population in Japan. We assumed the winter season for the worst case when the river flow rate is the lowest. The amount of $\mathrm{C}_{6} \mathrm{H}_{12} \mathrm{~N}_{4}$ taken into the water treatment plant was calculated using the AISTSHANEL ver.3.0 model [1] based on advection-diffusion analysis. We estimated the concentration of $\mathrm{CH}_{2} \mathrm{O}$ produced by the chemical reaction from the concentration of $\mathrm{C}_{6} \mathrm{H}_{12} \mathrm{~N}_{4}$ in the water purification tank and assess the risk of water suspension by comparing the generated $\mathrm{CH}_{2} \mathrm{O}$ concentration with water quality standards.

Our results showed that $5,934 \mathrm{~kg}$ of $\mathrm{CH}_{2} \mathrm{O}$ would be generated in the water treatment tank in case that $4,600 \mathrm{~kg}$ of $\mathrm{C}_{6} \mathrm{H}_{12} \mathrm{~N}_{4}$ has spilled out. The detailed simulation results will be discussed in the poster.

[1]The Research Institute of Science for Safety and Sustainability (2015). 